\title{
A Pluralidade Linguístico-cultural do Italiano e o SilÈncio dos Materiais Didáticos
}

\author{
Cristiane Landulfo* \\ Alessandra Paola Caramori \\ Adriane Viana
}

RESUMO: O italiano é convencionalmente difundido como língua nacional da Itália. No entanto, em outros países, esse idioma também tem o status de língua oficial, segunda língua e língua nacional. Partindo dessa premissa, o presente artigo tem o propósito de refletir sobre o que chamamos de pluralidade linguístico-cultural do italiano, bem como apresentar dados de uma pesquisa cujo objetivo foi verificar se e como os materiais didáticos de língua italiana mais utilizados pelos professores brasileiros que responderam ao nosso questionário contemplam essa pluralidade. $\mathrm{O}$ corpus deste estudo foi analisado sob o enfoque qualitativo-interpretativista. Os resultados demonstraram um total apagamento dos outros países.

PALAVRAS-CHAVE: Pluralidade linguístico-cultural do italiano; Materiais didáticos; Ensino do italiano.

ABSTRACT: Italian is conventionally considered as the national language in Italy. However, in other countries, this language also has the status of official language, second language or national language. Based on this idea, this article aims to reflect on what we call the Italian linguistic-cultural plurality, as well as discussing data from a research which goal was to analyze if and how the most used by Brazilian teachers who responded to our simple quiz consider this plurality. Thus, the qualitative and interpretative approach. The results showed a total deletion of the other countries.

KEYWORDS: Italian Linguistic-cultural plurality; Italian Textbooks; Teaching Italian.

ABSTRACT: L'italiano viene trasmesso ovunque come lingua ufficiale d'Italia.

* Universidade Federal da Bahia, Salvador (Brasil) - cristianelandulfo@gmail.com /

alecaramori@gmail.com / adrianesviana@hotmail.com

DOI: http://dx.doi.org/10.11606/issn.2238-8281.v0i36p58-70 
Tuttavia in altri paesi questo idioma ha anche lo status di lingua ufficiale, seconda lingua o, ancora, lingua nazionale. Partento da questo pressuposto, questo articolo è destinato a riflettere su ciò che noi chiamiamo pluralità linguistico-culturale dell'italiano, oltre a presentare dati di una ricerca il cui obiettivo era quello di verificare se e come i materiali didattici di lingua italiana più frequentemente utilizzati dagli insegnanti brasiliani che hanno risposto al nostro questionario includono questa pluralità. Il corpus di questo studio è stato analizzato sotto l'approccio qualitativo - interpretativo. I risultati hanno dimostrato una cancellazione totale degli altri paesi.

PAROLE-CHIAVE: Pluralità linguistico-culturale dell'italiano; Materiali didattici; Insegnamento dell'italiano. 


\section{Introdução}

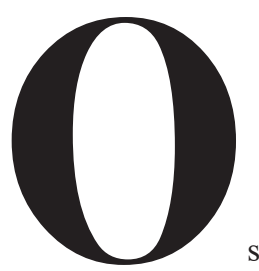

s materiais didáticos de língua estrangeira atuais estão cada vez mais sofisticados no que se refere à instrumentalização do processo (estética, fontes complementares, conteúdos digitais, etc.), porém, ainda apresentam grande dissonância, na distribuição de categorias como nacionalidades, profissões, etnias, distribuição de gênero, dentre outras. Ademais, privilegiam, majoritariamente, apenas uma variedade de língua de um dado país, geralmente, a variedade de prestígio.

Mas o fato é que é muito difícil pensarmos a prática pedagógica sem a utilização desses materiais didáticos. Na verdade, quando planejamos um curso, uma disciplina ou, apenas, uma única aula, um dos nossos primeiros passos é a seleção do material que será usado em sala de aula. Isso significa que eles acabam exercendo um papel de controle da aprendizagem.

No caso dos manuais de línguas estrangeiras, são esses que, em diferentes contextos educacionais, alimentam a base do conteúdo das aulas, regulam as habilidades que deverão ser trabalhas e, ainda, modelam a linguagem praticada pelos alunos. Além disso, em muitos casos, são ainda utilizados por muitos professores como a única fonte durante o processo de ensino e aprendizagem, transformando-os em única verdade. Em razão disso, entendemos que é urgente repensar o processo de ensino e aprendizagem de línguas em seus diferentes contextos sociais, culturais e políticos, considerando gênero, etnia e outras relações, bem como a concepção de sujeito como múltiplo e formado por diferentes discursos. Essa mudança deve perpassar todas as instâncias da sociedade, inclusive os livros didáticos que utilizamos em nossas salas de aulas.

Diante do exposto, investigamos em alguns manuais de Língua Italiana (doravante LI), temas que consideramos importantes para o conhecimento do italiano, bem como para a formação de um cidadão crítico, a saber: (1) pluralidade linguístico-cultural do italiano; (2) gênero; (3) família; (4) raça e etnia. A seleção desses manuais foi feita após a divulgação em ambiente virtual de um questionário-sondagem ${ }^{1}$ que foi respondido por 43 professores de italiano que atuam em diferentes contextos educacionais (cursos livres, escolas públicas, escola provadas e universidades). Após trinta dias de divulgação do referido questionário, analisamos as respostas dadas e concluímos que os cinco livros mais indicados formariam o corpus da nossa pesquisa.

Devido às diferenças de edição e o número de volumes entre os livros selecionados, optamos por analisar apenas aqueles que se referem ao nível elementar. Ou seja, o material didático des-

1 https://docs.google.com/forms/d/1j7oYSUeZrz6EwgAWS4IXPrlVfs0zcUNoQ4DzcTYj1i8/edit?c=0\&w=1\&fbclid=IwAR3etQ62s17wANpjzmS16b19zV1502aCm48VjAayxZKSNesUBeKHVDuRQkI\#responses>. 
tinado para aprendizes principiantes. Os livros selecionados para este estudo foram:

Quadro 1 - Os livros didáticos analisados

$$
\begin{aligned}
& 56,4 \% \text { NUOVO PROGETTO ITALIANO } \\
& 38,5 \% \text { NUOVO ESPRESSO } \\
& \text { 15,4\% DIRE, FARE E PARTIRE } \\
& 10,3 \% \text { NUOVO CONTATTO } \\
& 10,3 \% \text { RETE }
\end{aligned}
$$

Neste artigo, por uma questão de espaço e escopo, nos concentraremos apenas nos dados referentes à primeira categoria de análise, pluralidade linguístico-cultural do italiano, que será discutida a fim de que o leitor possa compreendê-la.

\section{Pluralidade linguístico-cultural do italiano}

$\mathrm{Na}$ Itália, a atual paisagem linguístico-cultural e as recíprocas conexões entre língua e 'dialetos' mudaram em relação ao passado, mas não por isso são mais simples. Marazzini (2004, p. 431) sintetiza essa realidade linguístico-cultural claramente quando faz a seguinte afirmação: "o italiano não é falado de forma uniforme em todo o território nacional". Por exemplo, o italiano falado em Milão tem diferenças em relação àquele que é falado em Nápoles, na Sardenha, em Veneza, e, sobretudo, na Suíça. Segundo Lorenzetti (2002), esses falares são geralmente influenciados, dentre outros fatores, pelos 'dialetos' locais. Os quais, conforme Coseriu (1982, p. 10), configuram um "modo de falar interindividual" e atualmente são usados em áreas geográficas bem específicas. Por essa razão, recebem essa nomenclatura, porque, diferentemente da língua nacional, não gozam de um estatuto sociocultural e político e não são reconhecidos pelo Estado. Neste artigo, usamos, todavia, o termo língua e o termo 'dialeto' apenas porque assim eles são conhecidos, mas, em hipótese alguma, para cotejá-los ou hierarquizá-los.

Mas quais são as variedades do italiano, língua nacional, e quais são os diversos 'dialetos' que compõem o complexo mosaico linguístico da Itália contemporânea? Na tentativa de obter respostas para esses questionamentos, muitos estudiosos ao longo dos anos, Mioni (1985), Sabatini (1985) e Berruto (1987), apresentaram uma diversidade de modelos sobre o repertório linguístico dos italianos.

No século passado, Mioni (1985) apresentou um modelo que contempla sete variedades do italiano: standard formal, standard coloquial-formal, italiano regional, italiano popular regional e três para os dialetos da Itália ${ }^{2}$ : dialeto formal, dialeto informal urbano e dialeto informal rural. Na década de 80 do mesmo século, Sabatini (1985) propôs um modelo com seis variedades: duas "nacionais" - o italiano standard e o de uso médio - e quatro "regionais e

2 De acordo com Avolio (2011, apud FREIRE et al, 2015, p. 756), os dialetos não deveriam ser considerados filhos do italiano, e sim seus irmãos. Dessa forma, seria impróprio falar de "dialetos italianos", mas, como sugere o autor, seria mais oportuno o conceito de "dialetos ítalo-românicos" ou "dialetos da Itália". 
locais" - o italiano regional culto, o regional popular, além de dialeto regional. Berruto (2003, p.14-15), mais recentemente, singulariza diversas variedades, dentre elas: o italiano standard, neostandard, popular e regional.

De acordo com Santoro e Frangiotti (2013), existem ainda outras variedades: o italiano denominado culto, empregado por falantes de nível sociocultural médio-alto e alto, variedade muito próxima do chamado italiano standard; o italiano dos jovens, que é a variedade usada por indivíduos de 13 a 21 anos, recheada de gírias e itens lexicais típicos dos dialetos da Itália; e, finalmente, as chamadas línguas especiais, empregadas em determinados setores, tais como a medicina, a arquitetura, a engenharia, a biologia, entre outros.

Mas além dessa diversidade que permeia o italiano falado na Itália é importante informarmos que esse idioma, conhecido mundialmente como a língua da península italiana, não é língua oficial apenas na Itália e, muito menos, falado apenas nesse país. Esclarecemos, portanto, que:

O italiano é língua oficial na Itália, na Croácia, na Suíça, na Eslovênia, no Vaticano e em San Marino. Além disso, o italiano é falado por parte significativa da população, sendo, portanto, uma das línguas nacionais, na Albânia, onde é a língua mais ensinada nas escolas; em Malta, na Córsega, em Nice, no Principado de Mônaco, Eritreia (falada em nível de segunda língua e como língua nacional), na Somália, na Líbia e na Etiópia. E em menor escala, nas comunidades de descendentes de imigrantes italianos no Brasil, Argentina, Uruguai, Venezuela, Austrália, México, Canadá, Estados Unidos, Alemanha, França, Bélgica, Reino Unido e Luxemburgo ${ }^{3}$ (LANDULFO, 2012, p. 116).

Em Malta, por exemplo, essa língua é falada e compreendida pela maior parte da população, especialmente, por causa da sua difusão tanto na televisão quanto no ensino nas escolas e na universidade. Além disso, o italiano, juntamente com o inglês, era a língua oficial nesse país até 1934. Atualmente, existe uma comunidade em uma rede social - "Reintroduciamo ufficialmente la língua italiana a Malta" - que reivindica a adoção do italiano como língua oficial do país, pois segundo os seguidores dessa comunidade virtual, os malteses são falantes reais desse idioma.

Em uma pesquisa sitiográfica, encontramos uma narrativa contada por uma professora de italiano que ilustra a presença desse idioma em outras partes do mundo:

[...] queria compartilhar com vocês uma experiência bem interessante que tive quando comecei a estudar alemão aqui na Suíça. No primeiro dia, quando entrei na sala de aula, percebi que havia um grupo de três mulheres que falavam uma língua diferente, que logo conclui que deveria ser algum dialeto

3 Essas informações podem ser vistas nos seguintes sites: <http://www.cursoitaliano.net/ptitalian/facts.asp >;http://www.linguagest.com/HTML/quem_so os/linguas_romanicas.htm $>$; $\quad<$ http : :/italiano.forumdeidiomas.com. br/2011/09/a-lingua-italiana-no-mundo $>$. E nos livros, La língua Italiana: profilo storico, de Claudio Marazzini, Il Mulino, 1994, e Elementos de filologia românica, de Bruno Bassetto, EDUSP, 2001. 
africano, a julgar pela aparência e pelas roupas que elas usavam. Fiquei muito curiosa, pois era a primeira vez que ouvia um dialeto africano assim "in diretta". Contudo, o mais curioso era que, em meio àquelas palavras para mim completamente incompreensíveis, saltavam algumas palavrinhas italianas do tipo "ecco", "allora", "va bene". A minha curiosidade foi tanta que não aguentei e me aproximei delas, tentando, inicialmente, comunicarme em inglês, mas nenhuma delas entendia. Nesse meio tempo, chegou uma menininha bonitinha e chamou uma delas de "mamma", e ela lhe respondeu "dimmi, cosa vuoi?", com um italiano, digamos, "africanizado", com uma cadência muito dura e bem diferente do italiano falado na Itália, mas era italiano. Foi quando eu perguntei: "come mai parli italiano?", e ela, com muita propriedade, me respondeu "é la lingua del mio paese". O país era a Eritreia, que, para a meu total surpresa e ignorância, naquele momento, eu nem sabia (ou não me lembrava) em que parte da África ficava (LOPES, 2011, grifo nosso $)^{4 *}$

Como visto, essa situação mostra claramente que a LI é falada em muitas outras comunidades, além daquelas conhecidas, como a Itália e a Suíça, país no qual o italiano é usado em toda a região de Cantão Ticino e nos quatro vales da região de Grigioni. Nesse caso, é muito importante ressaltar que se trata de uma língua nacional fora da Itália, construída, de acordo com Moretti (2011), por suas variedades faladas e escritas.

Segundo um recenseamento de 2000, apontando por Lüdi (2005), cerca de 550.000 mil pessoas declararam que o italiano é uma das línguas principais da Suíça. Dessas, 347.000 são emigrantes e 110.000 mil vivem na chamada Suíça Italiana. De acordo com os dados apresentados, os italófonos das três regiões não italófonas constituem cerca de 292.000 mil. Na chamada Suíça Alemã, o italiano também se destaca entre os trabalhadores estrangeiros, em espacial, após a segunda metade do século XX (MARELLO, 2012). Isso ocorre, não somente por motivos ligados ao turismo, ao Made in Italy e à cultura italiana em geral, mas principalmente por razões estreitamente profissionais, uma vez que esse idioma é falado por muitos trabalhadores, especialmente emigrantes do setor terciário, como açougueiros, profissionais liberais e médicos e em setores como a gastronomia, construção civil e a indústria têxtil (SCHIMID, 1993).

Não podemos esquecer que o italiano também é uma das línguas oficiais da Eslovênia, falado como segunda língua mais precisamente nas cidades litorâneas de Ancarano, Piran, Izola e Ístria. No território istriano, por exemplo, esse idioma é a língua materna do grupo étnico italiano e língua do ambiente social para outros cidadãos. Ademais, para favorecer o bilinguismo e fornecer aos emigrantes italianos e seus descendentes o acesso ao aprendizado do idioma de seu país de origem, as autoridades slovenas introduziram o ensino da LI tanto na escola infantil, quanto nas séries mais avançadas. Além disso, revistas e jornais italianos na Eslovênia são distribuídos em muitas lojas. Existe, ainda, um canal televisivo e radiofônico, o RTV Koper

4 Disponível em: <http://italiano.forumdeidiomas.com.br/2011/09/a-lingua-italiana-no-mundo/>. Acesso em: $13 / 03 / 2015$ 
Capodistria, que transmite programas no idioma italiano.

Na Croácia, mais exatamente na região da Ístria croata, o italiano standard é a língua nacional difundida na televisão, nos jornais, nas escolas e nas universidades, embora a comunidade italiana e os falantes de LI como língua materna estejam diminuindo, conforme os dados do Censo de 2001 (MIKLIC, 2001). Vale ressaltar, contudo, que os 'dialetos' da Itália são bastante falados nesse país, em especial, o ‘dialeto’ istroveneto, que para muitos italófonos da região é a língua de família.

Apesar da realidade croata comprovar que o italiano é pouco usado pela comunidade local, permanece em vigência o bilinguismo italiano/croata, pelo menos oficial e institucionalmente, nas seguintes cidades: Buie, Cittanova, Dignano, Parenzo, Pola, Rovigno, Umago, Valle d'Istria, Verteneglio, Fasana, Grisignana, Castellier-Santa Domenica, Lisignano, Montona, Portole, Visignano, Visinada e Orsera.

Os italianos residentes na Croácia, juntamente com os italianos da Eslovênia, constituem a Comunidade Nacional Italiana (CNI) autóctone. Trata-se de uma comunidade estruturada organicamente com numerosas instituições espalhadas em todo o território nacional que buscam com as suas atividades manter viva a cultura, a língua e a identidade italianas, transmitindo-as às novas gerações.

Na França, o italiano é compreendido por boa parte da população Corsa, devido principalmente a razões histórico-geográficas e às semelhanças entre a língua corsa e os 'dialetos' toscanos. O mesmo pode-se dizer do Principado de Mônaco, onde a comunidade italiana corresponde a $21 \%$ da população e o italiano é L2 após o francês e o monegasco. Já na Albânia, a difusão e o bom conhecimento desse idioma se dão graças aos meios de comunicação. Além dessas cidades, o italiano foi disseminado, consequentemente, nas ex-colônias italianas africanas: Líbia, Eritreia, Etiópia e Somália. Vale ressaltar que nesse último país, o italiano foi língua oficial até 1963.

Mas onde estão essas nações nos manuais de italiano para estrangeiros? A fim de responder a essa pergunta foram analisados os materiais mais utilizados pelos professores de italiano no Brasil que responderam ao nosso questionário.

\section{O silêncio dos materiais didáticos de italiano}

Com os livros em mãos, demos início às análises com o propósito de verificar como a pluralidade linguístico-cultural que defendemos é abordada pelos livros didáticos mais usados pelos professores brasileiros de LI, informantes da pesquisa. Vale ressaltar que nos debruçamos apenas nos livros do primeiro nível e somente na versão impressa, ou seja, não analisamos nem os áudios e nem os vídeos.

O livro mais usado, conforme as respostas ao nosso questionário-sondagem, é o Nuovo Progetto Italiano cuja publicação aconteceu em 2006. Trata-se de uma nova edição atualizada, 
dividida em dez unidades didáticas. A sua grande novidade, em relação às edições anteriores, é a inserção de um CD-ROM interativo que permite ao aluno estudar os conteúdos gramaticais e comunicativos em qualquer momento e não apenas na sala de aula. Nesse manual, além de termos constatado que não há nenhuma menção aos países falantes de LI, percebemos um total silenciamento em relação à Suíça, como é possível verificar na transcrição do diálogo a seguir:

Signore: Scusi, sa dov'è via Alberti?

Signora: No, non abito qui, sono stranieira.

Signore: Stranieira?! Complimenti! Ha una pronuncia tutta italiana! Se permette, di dov'è?

Signrora: Sono svizzera.

Signore: Ah, ed è qui in vacanza?

Signora: Sì, ma non è la prima volta che visito l'Italia.

Signore: Ah, ecco perché parla così bene l'italiano. Allora...arrivederLa, signora. ArrivederLa ${ }^{5}$. (NUOVO PROGETTO ITALIANO, 2006, p. 24, grifo nosso).

Na transcrição do diálogo, podemos verificar um silencimento ou um claro desconhecimento de que na Suíça, conforme Elisa Pestoni (2015), em seu trabalho, entitulado "L'italiano in Svizzera: più lingua nazionale e ufficiale o più lingua di minoranza? Politiche linguistiche, iniziative in sua difesa e modalità d'insegnamento ${ }^{6}$ ", o italiano é falado nesse país em diferentes áreas, para diversas finalidades e permeado por suas variedades que o distingue do italiano falado na Itália. Conforme já mencionado, na conhecida Suíça Italiana, especificamente no Cantão Ticino e nos quatro vales do Cantão Grigioni, o italiano da Suíça, segundo Fantuzzi (1996, p.12), é uma língua de fronteira, visto que compreende "todos os fenômenos produzidos pelo contato entre línguas diferentes".

Nesse país, de acordo com as explicações de Pestoni (2015), o italiano possui várias características, sendo, portanto, classificado em: (1) italiano 'federal' ou 'helvético', um italiano que possui características particulares e é usado em contextos institucionais, inclusive em Berna; (2) o italiano conhecido como 'pouco natural', por ser o resultado de traduções realizadas na esfera privada e que é perceptível, por exemplo, nos produtos à venda, nos recibos de pagamento e nos outdoors; (3) o italiano entendido como língua de imigração interna, falado fora da Suíça italiana por cidadãos nascidos em Ticino, Grigioni ou mesmo na Itália. (4) o italiano como língua franca, aquele falado por imigrantes não italófonos, denominado por Berruto (1991) de Fremdarbeiteritalienisch, que significa italiano dos trabalhadores estrangeiros.

Diante do exposto, entendemos que ao apresentar uma pessoa cuja proveniência é a Suíça,

5 Senhor: Com licença, senhora sabe onde fica a rua Alberti?

Senhora: Não, não moro aqui, sou estrangeira.

Senhor: Estrangeira?! Parabéns! Tem uma pronúncia toda italiana! Se me permite, qual a sua nacionalidade?

Senhora: Sou suíça.

Senhor: Ah, está de férias aqui?

Senhora: Sim, mas não é a primeira vez que venho à Itália.

Senhor: Ah, é por isso que fala tão bem italiano. Então...Até logo, senhora.

Senhora: Até logo (NUOVO PROGETTO ITALIANO, 2006, p. 24, tradução nossa).

6 O Italiano na Suíça: mais língua nacional e oficial ou mais língua de minoria? Políticas linguísticas, iniciativas em sua defesa e modalidades de ensino. 
o referido material deveria ter, pelo menos, mencionado que o italiano é uma das línguas oficiais desse país. Mas, ao contrário disso, considerou que a estrangeira fala bem a LI porque já visitou a Itália várias vezes. Fica então a pergunta: qual a intenção desse silenciamento?

O segundo livro mais indicado foi o Nuovo Espresso que também foi publicado por uma grande editora italiana situada em Florença, Alma Edizioni. Assim como o Nuovo Progetto, trata-se de uma edição renovada de 2014 e dividida em 10 unidades didáticas complementadas pelo chamado DVD multimídia. No referido manual, é possível verificar o destaque aos mais diferentes aspectos da Itália, como demostram alguns títulos das suas unidades didáticas: In giro per L'italia, Sapori d'Italia. Em diversas passagens do livro é possível observar a ênfase dos aspectos culturais de um único país. Como por exemplo, nas seções denominadas de Caffè Culturale, nas quais encontramos notícias da Itália, as três cidades mais visitadas da Itália, como são as férias na Itália, como funciona a gorjeta na Itália. Enfim, não há, portanto, nenhuma menção às outras comunidades falantes de LI, mas, apenas, uma ênfase total em uma única nação.

O terceiro material, Dire, Fare e Partire com 15,4\% das indicações, é o único material de italiano produzido no Brasil por uma professora e pesquisadora da Universidade de São Paulo (USP) e voltado, especificamente, para aprendizes brasileiros. É um material recente, disponibilizado gratuitamente em ambiente virtual e que além dos 16 episódios didáticos que contemplam conteúdos gramaticais e comunicativos, possui entrevistas feitas com especialistas sobre diversos temas relacionados ao processo de aprendizagem da LI, tais como: dificuldades de aprendizagem, o uso do dicionário e de filmes italianos para o processo de ensino/aprendizagem do italiano e comunicação intercultural.

Dire, Fare, Partire! É um conjunto de materiais didáticos gratuitos - vídeos, apostilas e material multimídia -, elaborado especificamente para alunos e professores brasileiros de italiano, que pode ser utilizado como recurso para a autoaprendizagem, sem tutoria, ou em sala de aula presencial, com a mediação de um professor. Este primeiro módulo é composto por 16 aulas, sendo que cada aula é dividida em duas partes. Na primeira parte, há uma série de ficção que aborda as dificuldades linguísticas e culturais típicas de um aluno brasileiro que estuda italiano no Brasil. Entre as cenas do episódio, o professor focaliza as dificuldades enfrentadas pelos personagens e apresenta elementos linguísticos e culturais relativos a cada módulo. Na segunda parte, o professor recebe no estúdio um convidado para uma entrevista sobre aspectos linguísticos ou culturais. As entrevistas são em italiano, para que, aos poucos, você se possa se acostumar com o ritmo normal de uma conversação em italiano e você pode acompanhar a transcrição em PDF. (BACCIN, 2015)7

7 Acesso em 04 de fevereiro de 2017. Disponível em: <http://cursosextensao.usp.br/course/view.php?id=131>. 
Esse material conta a história de um brasileiro, descendente de italianos que deseja conhecer a Itália, país de seus ancestrais. O curso é, portanto, baseado em uma história de ficção que narra o processo de aprendizagem do italiano vivenciado pelo personagem principal da trama, bem como os preparativos para a sua viagem ao Bel paese. Todavia, apesar da trama estar voltada para a viagem à Itália, é possível verificar a informação de outra comunidade falante do italiano, como na figura a seguir:

Fig. 1 - Dire, Fare, Partire! (aula 2)

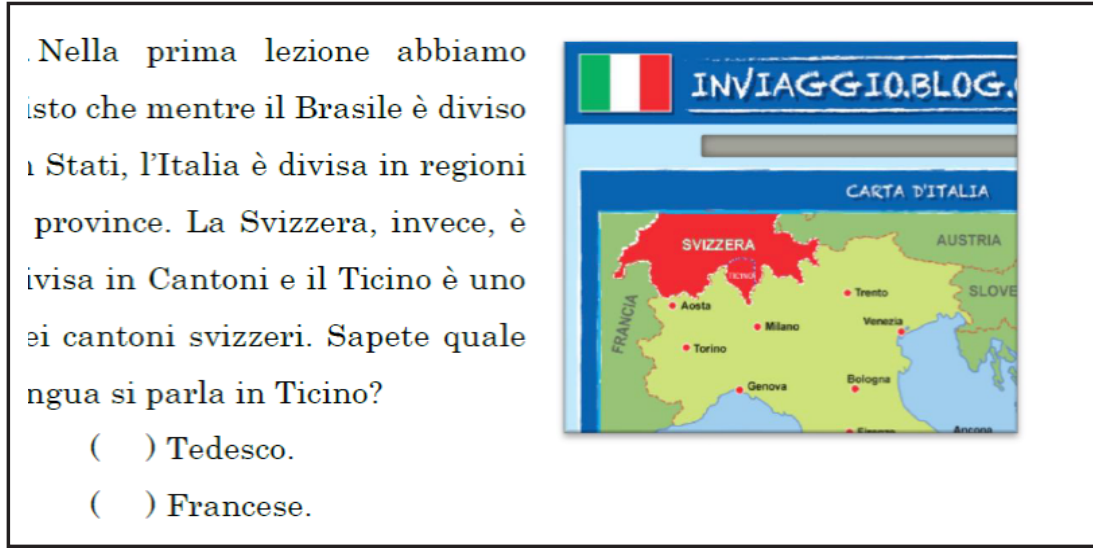

Fonte: Baccin (2015)

Encontrar essa informação durante a nossa investigação foi extremamente importante, pois, apesar de ser uma pequena menção ao Cantão Ticino, nos revela que a autora desse material didático compreende a pluralidade linguístico-cultural do italiano e por essa razão busca apresentá-la aos aprendizes brasileiros.

Contudo, é importante ressaltar que a figura ilustra muito pouco a situação do italiano falado em Ticino cuja Constituição, em seu artigo primeiro, afirma que Cantão Ticino é uma República democrática de língua e culturas italianas e que a única língua oficial é o italiano (PESTONI, 2015). Pestoni (2015) explica em seu trabalho que, atualmente, o chamado italiano regional ticinese (IRT), está perdendo muitos traços dialetais e vem apresentando semelhanças com italianos regionais setentrionais, ainda que as características do italiano helvético não tenham desaparecido.

O quarto livro, Nuovo Contatto A1, foi publicado pela editora italiana Loescher de Turin em 2014. Esse manual, diferentemente dos outros, está dividido em apenas cinco unidades. Entretanto, assim como nos demais, não encontramos nenhuma menção aos outros países nos quais o italiano é falado. Há, contudo, uma ênfase nos elementos culturais da Itália. Existem seções 
nas quais são apresentados aos aprendizes de LI, os nomes e os gestos dos italianos, as cidades turísticas italianas, a importância dos avós para as famílias italianas, as tendências alimentares italianas, etc.

O quinto e o último livro, publicado pela editora Guerra Edizioni em 2000, é intitulado curso multimídia de italiano para estrangeiros e é divido em 15 unidades didáticas. Nesse livro também não encontramos referência à Suíça, à Eslovênia ou a qualquer outra comunidade falante de LI. Assim com os outros materiais analisados, há uma ênfase na geografia italiana, no clima da península italiana, no comportamento dos italianos, nos personagens famosos da Itália, nos meios de transportes da Itália, etc.

Por fim, devemos informar que em todos os livros usados para o processo de ensino e aprendizagem da LI que foram investigados, não encontramos referências às variedades do italiano falado na Itália, as quais foram apresentadas na segunda seção deste artigo.

\section{Considerações finais}

Pelo o que foi verificado na análise dos livros didáticos eleitos como os mais usados pelos informantes da pesquisa, durante a nossa sondagem realizada em janeiro de 2017, a pluralidade linguístico-cultural do italiano não é contemplada, ou seja, os demais países nos quais a LI é falada são completamente negligenciados e silenciados por esses materiais. Eis que, aqui, fazemos os seguintes questionamentos:

- Por que esses países são ignorados?

- Por que não há nenhuma menção a essas outras comunidades falante de LI?

- Por que somente o material publicado no Brasil faz menção a Suíça?

- Como os aprendizes de língua italiana poderão ter acesso às particularidades do italiano falado em outros países se os livros por eles usados sequer mencionam o nome das diferentes nações?

- Como é possível ter acesso às outras culturas da língua-alvo se essas são silenciadas?

- Como a pluralidade linguístico-cultural pode ser trabalhada em sala de aula se a maior parte dos livros mais usados pelos professores de italiano no Brasil não propiciam esse conhecimento?

De acordo com Santipolo $(2001,2010)$, em diferentes países, o modelo seguido para o ensino do italiano é quase exclusivamente o standard, língua padrão, ou, mais recentemente, o neostandard, uma nova língua padrão. Quer seja pelo uso de material didático que desconhece os diferentes e reais ambientes de ensino e aprendizagem e ignora os demais países onde o italiano é falado, quer seja por professores que, por vários motivos, dentre estes a própria formação, impossibilitam o acesso dos aprendizes à "língua viva" e à diversidade cultural (LANDULFO, 2016). Em razão disso, Santipolo (2001)declara que nenhum curso de italiano L2/LE pode ser completo, se a pluralidade linguístico-cultural desse idioma não for considerada. 
Outras pesquisadoras brasileiras conscientes dessa multiplicidade realizaram uma pesquisa cujo objetivo foi verificar se aprendizes brasileiros de LI seriam capazes de identificar as variedades do italiano e os 'dialetos' da Itália presentes em seis cenas de um filme italiano. Após apresentarem os resultados desse estudo, as duas pesquisadoras concluíram que diante da complexidade do quadro linguístico da Itália contemporânea,

[...] seria desejável que os aprendizes aprendessem não apenas registros e variedades “médias", mas também que entrassem em contato com a pluralidade de variedades regionais e de registros, além de desenvolver a capacidade de reconhecer os dialetos como "outras" línguas. A Itália linguística "real" é feita de tudo isso e aprender a (re) conhecer apenas uma pequena parte de sua complexidade significaria perder a riqueza que a constitui (SANTORO e FRANGIOTTI, 2013, p. 245).

Concordamos com as palavras de Santipolo (2001), Santoro e Frangiotti (2013), todavia as complementamos, postulando que além de olharmos para o quadro linguístico da Itália contemporânea, é preciso nos voltarmos para outras culturas e países onde o italiano está presente ou como L2 ou como língua oficial. Pois, segundo os Parâmetros Curriculares Nacionais - PCN (1998), aprender línguas é uma oportunidade de conhecer outras culturas, e dessa forma, é preciso inserirmos a pluralidade linguística e cultural nos cursos e nas aulas de LI e obviamente, nos materiais didáticos de italiano para estrangeiros. Concentrar-se apenas na Itália, significa reduzir essa oportunidade.

Informar aos aprendizes o lugar que o italiano ocupa no mundo é permitir que esse mundo entre para as salas de aula e faça parte do processo de ensino e aprendizagem. Precisamos, portanto, olhar para outros lugares, tais como a África, a Suíça, a Eslovênia e para outras comunidades falantes de LI. Afinal, aprender uma língua estrangeira é uma oportunidade de conhecer outras formas de ver o outro diferente de nós. Isso significa, aprender a estar e ser dentro da diversidade. Enfim, entendemos que como professores, devemos propiciar um ensino mais plural e culturalmente sensível.

\section{Referèncias}

BACCIN, P. Dire, Fare, Partire. USP, 2015. Disponível em: <http://cursosextensao.usp.br/course/ view.php?id=131>. Acesso em 05/03/2017

BERRUTO, G. Sociolinguistica dell'italiano contemporaneo, Roma: La Nuova Italia Scientifica, 1987, pp. 19-27; 33-36.

Fremdarbeiteritalienisch: fenomeni di pidgninizizzazione dell'italiano nella Svizzera

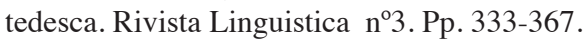

, G. La Varietà del repertorio. In: SOBRERO, A. A. Introduzione all'italiano contemporaneo. Roma: Editora Laterza, 2003.

BOZZONE, R. GHEZZI, C. Nuovo contatto A1: Corso di lingua e civilta italiana per stranieri. Edi- 
tora: LOESCHER: 2014.

COSERIU, E. O homem e a sua linguagem. Trad. Carlos Alberto da Fonseca e Mário Ferreira. Coleção Linguagem. Rio de Janeiro: Presença, 1982.

FANTUZZI, M. "Ma che lingua parliamo (e scriviamo)? Italiano di Svizzera e traduzioni", "Portico: inserto culturale" La Sinistra No2, pp. 12-13, 1996

LANDULFO, C.M.C.L.S. Cultura de aprender: investigando as crenças e as ações dos alunos de língua italiana da UFBA. 2012. Dissertação de mestrado. Universidade Federal da Bahia (UFBA), Salvador (BA).

. Currículo e formação inicial dos professores de italiano no Brasil: constatações e reflexões. Tese de Doutorado. 2016. Universidade Federal da Bahia (UFBA), Salvador (BA).

LORENZETTI, L. L'italiano Contemporaneo. Roma: Carocci, 2002.

LÜDI, G. Censimento federale della popolazione 2000: Paesaggio linguistico in Svizzera. Neuchâtel: UST, 2005.

MARAZZINI, C. Breve storia della lingua italiana, Bologna: Il Mulino 2004.

MARELLO, C. Corpora di apprendenti: Come usarli nella didattica dell'italiano in Svizzera; In: PIERO A. Di PRETORO, LUKOSCHIK, R.U. Lingua e letteratura italiana 150 anno dopo l'Unità. Monaco: Meidenbauer 2012, p. 299-315.

MARIN, T. E MAGNELLI, S. Nuovo Progetto Italiano 1. Roma: Edizioni Edilingua, 2006.

MEZZADRI, M. BALBONI, P. E. Rete! Perugioa, Guerra Edizioni, 2000.

MIKLIC, T.; OZBOT, M. L'insegnamento dell'italiano in Slovenia. 2001. Disponível em: <https:// doc.rero.ch/record/18371/files/08_Miklic_Ozbot.pdf>. Acesso em: 10 de jan. 2015.

PESTONI, E. L'italiano in Svizzera: più lingua nazionale e ufficiale o più lingua di minoranza? Politiche linguistiche, iniziative in sua difesa e modalità d'insegnamento. Dissertação de Mestrado. Maîtrise : Univ. Genève, 2015.

SABATINI, F. L'italiano dell'uso medio: una realtà tra le varietà linguistiche italiane. In: Holtus-Radtke 1985, p. 154-84.

SANTIPOLO, M, Insegnare l'italiano o la pluralità dell'italiano? In: iT, nº 3, 2001, p.9-11.

SANTORO, E. FRANGIOTTI, G. A. Variedade linguística e ensino de língua italiana: uma experiência em sala de aula. In: Cadernos de Letras da UFF - Dossiê: Língua em uso, 2013, nº 47, p. 223-246

SCHIMID, S. Lingua madre e commutazione di codice in immigrati italiani di seconda generazione nella Svizzera tedesca. In: Revista Multilingua, v. 12. 1993, p. 265-289.

ZIGLIO, L. e RIZZO. Nuovo Espresso I. Firenze, Alma Edizioni, 2014.

Recebido em: 09/06/2018

Aprovado em: 30/10/2018 